BULLETIN Bulletin hispanique

HISPANIQUE Université Michel de Montaigne Bordeaux

123-2 | 2021

Investigaciones semánticas y léxicas actuales

\title{
Mechtild Albert, Victoria Aranda Arribas, Leonardo Coppola (eds.), La narrativa de Alonso Jerónimo de Salas Barbadillo
}

Berlín: Peter Lang, 2020

\section{Anne Cayuela}

\section{(2) OpenEdition}

Journals

Edición electrónica

URL: https://journals.openedition.org/bulletinhispanique/14599

DOI: 10.4000/bulletinhispanique. 14599

ISBN: 1775-3821

ISSN: $1775-3821$

Editor

Presses universitaires de Bordeaux

Edición impresa

Fecha de publicación: 20 diciembre 2021

Paginación: 391-393

ISBN: 979-10-300-0-745-9

ISSN: 0007-4640

Referencia electrónica

Anne Cayuela, «Mechtild Albert, Victoria Aranda Arribas, Leonardo Coppola (eds.), La narrativa de Alonso Jerónimo de Salas Barbadillo», Bulletin hispanique [En línea], 123-2 | 2021, Publicado el 20

diciembre 2021, consultado el 07 febrero 2022. URL: http://journals.openedition.org/

bulletinhispanique/14599; DOI: https://doi.org/10.4000/bulletinhispanique.14599

Este documento fue generado automáticamente el 7 febrero 2022.

Tous droits réservés 


\title{
Mechtild Albert, Victoria Aranda Arribas, Leonardo Coppola (eds.), La narrativa de Alonso Jerónimo de Salas Barbadillo
}

Berlín: Peter Lang, 2020

\author{
Anne Cayuela
}

\section{REFERENCIA}

Mechtild Albert, Victoria Aranda Arribas, Leonardo Coppola (eds.), La narrativa de Alonso Jerónimo de Salas Barbadillo, Berlín: Peter Lang, 2020, 320 p. (Bonner Romanistische Arbeiten, 121). ISBN : 978-3-631-83254-7

1 Este volumen colectivo reúne las doce contribuciones presentadas en el marco de un seminario celebrado en la universidad de Pescara en 2019 con el fin de arrojar luz sobre la narrativa de Alonso Jerónimo de Salas Barbadillo, autor del Barroco injustamente olvidado hasta épocas recientes, a pesar de la riqueza, la variedad y el carácter experimental de su obra narrativa, lírica y teatral. El examen de la naturaleza híbrida de sus libros, la necesidad de estudiar sus textos menos atendidos, y la voluntad de aportar nuevas claves de interpretación constituyen los enfoques más importantes de este volumen colectivo, que reúne a estudiosos expertos en la materia, muchos de ellos excelentes editores de narrativa áurea en la colección Prosa Barroca (Sial Pigmalión) ${ }^{1}$. Los artículos siguen el orden cronológico de la fecha de publicación de las obras, lo que permite arrojar luz sobre las influencias y fuentes de Salas (en particular las provenientes de los novellieri) y destacar la evolución de su creación literaria en cuanto a formas genéricas.

2 En el primer artículo, David González Ramírez muestra cómo El caballero perfecto (1620) remite al género de los manuales de cortesanía en la línea del Cortegiano de Castiglione 
y de sus imitaciones españolas. Esta importante investigación, designada por su autor como un "acercamiento parcial y provisional", permite entender cómo la fusión lograda por Salas Barbadillo entre tratado de cortesanía y novela constituye un eslabón decisivo puesto que, en el Siglo de Oro, el discurso cortesano ya no se limita a tratados de cortesanía, libros de avisos, sátiras, colecciones de sentencias o de emblemas, sino que migra hacia la ficción literaria.

Ilaria Resta aborda las traducciones de Don Diego de noche y El necio bien afortunado ${ }^{2}$ y de manera más general la recepción de Salas Barbadillo en Italia que define como "un provechoso recorrido de ida y vuelta" y "un diálogo fértil y dinámico". Muestra en efecto cómo Salas supo atraer la atención de algunos

editores italianos interesados en apostar por una fórmula experimentadora y también arroja luz sobre una interesante figura de traductor, Girolamo Brusoni.

Corrección de vicios y su ingeniosa ejemplaridad es objeto de un estudio de Maria Rosso en el que se destaca una narración doble: una asumida por un doble literario del propio Salas Barbadillo, a la vez autor y personaje, narratario de un segundo narrador loco y elocuente, "boca de todas verdades", que despliega dos niveles de narración : uno que remite al mundo "real", otro de carácter ficticio.

5 El marco narrativo de la Casa del placer honesto, sus complejidades y sus "líneas enmarcadoras" son objeto de un minucioso estudio de Fernando Copello que demuestra la índole experimental de la obra, así como las ambigüedades de esta casa exclusiva y absolutamente masculina.

6 Manuel Piqueras Flores analiza el género de la novela El sutil cordobés Pedro de Urdemalas y su "flexibilidad estructural" que "muestra el cambio de paradigma en el desarrollo de la prosa de ficción barroca": si bien dominan rasgos de la novela picaresca, la cornice de carácter académico en la que se insertan ficciones dentro de la ficción también constituye la armazón principal de esta obra. La originalidad de Salas Barbadillo en cuanto al tratamiento del género picaresco constituye una de las principales aportaciones del volumen. Marcial Rubio Árquez estudia el influjo de las obras canónicas -Lazarillo de Tormes y Guzmán de Alfarache- sobre El necio bien afortunado, y sobre todo su peculiar habilidad para reciclar materiales provenientes de diversas obras en una especie de "puzle, de arcimboldo de géneros y obras".

7 La picaresca femenina de Salas Barbadillo es objeto de un artículo de Victoria Aranda en el que se analizan las claves formales de su transposición televisiva en 1983 por Emilio Romero y Angelino Fons, o sea al final de la Transición democrática.

8 Giulia Giorgi se acerca al género teatral del entremés, y se fija en las diferencias entre las parejas de El juez de los divorcios de Cervantes (1615) y El decasamentero, incluido en Fiestas de la boda de la incasable malcasada (1622). Además de una diferente consideración de los personajes y de sus peculiaridades, la lengua que utilizan las parejas corresponden a códigos lingüísticos distintos, desiguales e incompatibles. Además Salas introduce matices y novedades en la caracterización de los personajes y en su habla, propias del contexto cortesano.

9 José Enrique Laplana Gil dedica un estudio a La estafeta del Dios Momo (1627) centrado en las distinta tipología epistolares firmadas respectivamente por Momo y Montano. Destaca la importancia de la agudeza verbal en las cartas jocosas, y la presencia de epitafios humorísticos en siete de ellas "en los que resulta difícil decidir si estos fueron 
escritos para rematar la carta o la carta lo fue para insertar un epitafio previamente escrito" (p.191). En las serias predomina el estilo elevado propio del encomio, la lisonjera búsqueda de protección. El artículo analiza la figura de Momo en comparación con su presencia en otras obras de Salas, y destaca el "empobrecimiento de su potencialidad irreverente y mordaz". Leonardo Coppola analiza la última obra publicada por Salas El curioso y sabio Alejandro, juez y fiscal de vidas ajenas (1634), una colección de seis novelas cortas cuyo hilo conductor es una galería artística que alberga la colección de los seis cuadros grotescos del caballero Alejandro, acompañados por epítomes biográficos de los retratados. Investiga con pertinencia la relación de estos retratos pictóricos y literarios con Paulo Jovio, Alciato, El Bosco y Quevedo.

El volumen se cierra con dos artículos sobre La peregrinación sabia, novela inserta en su miscelánea póstuma Coronas del Parnaso y platos de las musas $(1635)^{3}$. El primero de Mechtild Albert, co-editora del volumen, analiza las etapas y el sentido del viaje satírico de los dos zorros "que constituye una metaficción, o sea una mise en abyme de la obra en su totalidad" (p. 226) a la vez que "una crítica de la sociedad contemporánea" (p. 227). Revela también la hibridez genérica de la novela que remite tanto a la fábula de finalidad didáctica, a la novela italianizante, y a la novela satírica como a la novela picaresca. El itinerario de los dos zorros que les lleva a la prudencia se relaciona con el hecho literario, en un simbólico paseo metatextual por el campo literario. El segundo artículo (p. 241-317) proviene de la ingeniosa pluma de Rafael Bonilla Cerezo, coordinador del Proyecto de Excelencia I+D+i del MINECO La novela corta del siglo XVII: estudio y edición (y III) (FFI2017-85417-P) y director de la colección Prosa barroca. Se trata de un estudio definitivo sobre el proceso de composición y la estructura de la miscelánea ${ }^{4}$, que precede un análisis de la "pepitoria de géneros" que cocinó Salas, a partir del modelo picaresco "el más español y zorruno de toda la prosa áurea" (...) que constituye el esqueleto de La peregrinación sabia; el núcleo al que se sueldan el resto del los lances seudo-pastoriles, de caballería, académicos y costumbristas (p. 273). Arroja nuevas luces sobre aspectos ya trabajados por otros críticos: la academia de los animales, tras cuyas máscaras podrían esconderse Castillo Solórzano o José Pellicer, y la clave emblemática, que permite descifrar el alcance moral de las máximas diseminadas en el texto.

Un volumen imprescindible para quien quiera entender la producción novelística de Salas Barbadillo puesto que permite valorar adecuada y pertinentemente la hibridez genérica de sus obras en un contexto literario muy fértil y propenso a la autorrepresentación y a la metaficción.

\section{NOTAS}

1. Como señalé en la bibliografía de la prosa de ficción áurea que publiqué en mi libro Le paratexte au siècle d'or, Ginebra, Droz, 1994, p. 332-384, muchas novelas no disponían de ediciones modernas. La labor emprendida por esta magnífica colección viene a llenar un importante vacío. David González Ramírez y Manuel Piqueras Flores son editores de Correción de vicios, Giulia Gorgi de Noches de placer, Marcial Rubio Árquez de La huerta de Valencia, Rafael Bonilla de Tiempo de 
regocijo de Alonso de Castillo Solórzano y de Mojiganga del gusto de Andrés Sanz del Castillo. Cabe señalar también la edición, estudio y notas de José Enrique López Martínez, de El caballero puntual, de Alonso Jerónimo de Salas Barbadillo, Madrid, Real Academia Española - Centro para la Edición de los Clásicos Españoles, 2016, y la edición crítica de Don Diego de noche, al cuidado de Enrique García Santo Tomás, Madrid, Cátedra, 2013.

2. La autora no menciona el artículo de Giovanna Fiordaliso, «El necio bien afortunado de Salas Barbadillo y su traducción italiana», Studia aurea: revista de literatura española y teoría literaria del Renacimiento y Siglo de Oro, 2020, Vol.14, pp. 487-516 https://raco.cat/index.php/StudiaAurea/ index

3. Estoy preparando una edición de esta obra en la colección Prosa Barroca, Sial Pigmalión, que se publicará en 2022.

4. De hecho, matiza acertadamente algunas conclusiones mías publicadas en el artículo " Coronas del Parnaso y platos de las Musas de Alonso Jerónimo de Salas Barbadillo: una miscelánea polisinodal bajo el reinado de Felipe IV ", Mélanges de la Casa de Velázquez, Casa de Velázquez , 2013, 43 (2), pp. 69-94.

\section{AUTORES}

\section{ANNE CAYUELA}

Université Grenoble Alpes 